EGU2020-18838

https://doi.org/10.5194/egusphere-egu2020-18838

EGU General Assembly 2020

(c) Author(s) 2020. This work is distributed under

the Creative Commons Attribution 4.0 License.

\title{
Afforestation for climate change mitigation: Potentials, risks and trade-offs, and the role of biophysical climate effects
}

\author{
Jonathan Doelman ${ }^{1,2}$, Elke Stehfest ${ }^{1}$, Detlef van Vuuren ${ }^{1,2}$, Andrzej Tabeau $^{3}$, Andries Hof ${ }^{1,2}$, \\ Maarten Braakhekke ${ }^{4}$, David Gernaat ${ }^{1,2}$, Maarten van den Berg ${ }^{1}$, Willem-Jan van Zeist ${ }^{1}$, Vassilis \\ Daioglou $^{1,2}$, Hans van Meijl ${ }^{3}$, and Paul Lucas ${ }^{1,2}$ \\ ${ }^{1}$ PBL Netherlands Environmental Assessment Agency, The Hague, Netherlands \\ ${ }^{2}$ Copernicus Institute for Sustainable Development, Utrecht University, Utrecht, The Netherlands \\ ${ }^{3}$ Wageningen Economic Research, Wageningen University \& Research, The Hague, The Netherlands \\ ${ }^{4}$ Wageningen Environmental Research, Wageningen University \& Research, The Hague, The Netherlands
}

Afforestation is considered a cost-effective and readily available climate change mitigation option. In recent studies afforestation is presented as a major solution to limit climate change. However, estimates of afforestation potential vary widely. Moreover, the risks in global mitigation policy and the negative trade-offs with food security are often not considered. Here, we present a new approach to assess the economic potential of afforestation with the IMAGE 3.0 integrated assessment model framework (Doelman et al., 2019). In addition, we discuss the role of afforestation in mitigation pathways and the effects of afforestation on the food system under increasingly ambitious climate targets. We show that afforestation has a mitigation potential of 4.9 $\mathrm{GtCO}_{2} / \mathrm{yr}$ at 200 US $\$ / \mathrm{tCO}_{2}$ in 2050 leading to large-scale application in an SSP2 scenario aiming for $2^{\circ} \mathrm{C}\left(410 \mathrm{GtCO}_{2}\right.$ cumulative up to 2100$)$. Afforestation reduces the overall costs of mitigation policy. However, it may lead to lower mitigation ambition and lock-in situations in other sectors. Moreover, it bears risks to implementation and permanence as the negative emissions are increasingly located in regions with high investment risks and weak governance, for example in Sub-Saharan Africa. Our results confirm that afforestation has substantial potential for mitigation. At the same time, we highlight that major risks and trade-offs are involved. Pathways aiming to limit climate change to $2^{\circ} \mathrm{C}$ or even $1.5^{\circ} \mathrm{C}$ need to minimize these risks and trade-offs in order to achieve mitigation sustainably.

The afforestation study published as Doelman et al. (2019) excluded biophysical climate effects of land use and land cover change on climate, even though this is shown to have a substantial effect especially locally (Alkama \& Cescatti, 2016). As a follow-up to this study we implement the gridspecific temperature effects as derived by Duveiller et al. (2020) to the mitigation scenarios with large-scale afforestation to assess the effectiveness of afforestation for climate change mitigation as increased or reduced effectiveness may change cost-optimal climate policy. Notably in the boreal regions this can have a major effect, as transitions from agricultural land to forest are shown to have a substantial warming effect due to reduced albedo limiting the mitigation potential in these regions. Conversely, in the tropical areas the already high mitigation potential of 
afforestation could be even more efficient, as increased evapotranspiration from forests leads to additional cooling. However, it is uncertain whether the high efficiency of afforestation in tropical regions can be utilized as these are also the regions with high risks to implementation and permanence.

\section{References}

Alkama, R., \& Cescatti, A. (2016). Biophysical climate impacts of recent changes in global forest cover. Science, 351(6273), 600-604.

Doelman, J. C., Stehfest, E., van Vuuren, D. P., Tabeau, A., Hof, A. F., Braakhekke, M. C., .. Lucas, P. L. (2019). Afforestation for climate change mitigation: Potentials, risks and trade-offs. Global Change Biology

Duveiller, G., Caporaso, L., Abad-Viñas, R., Perugini, L., Grassi, G., Arneth, A., \& Cescatti, A. (2020). Local biophysical effects of land use and land cover change: towards an assessment tool for policy makers. Land Use Policy, 91, 104382.

How to cite: Doelman, J., Stehfest, E., van Vuuren, D., Tabeau, A., Hof, A., Braakhekke, M., Gernaat, D., van den Berg, M., van Zeist, W.-J., Daioglou, V., van Meijl, H., and Lucas, P.: Afforestation for climate change mitigation: Potentials, risks and trade-offs, and the role of biophysical climate effects, EGU General Assembly 2020, Online, 4-8 May 2020, EGU2020-18838, https://doi.org/10.5194/egusphere-egu2020-18838, 2020 